\title{
PERANCANGAN SISTEM UKURAN SEPATU UNTUK ANAK PEREMPUAN USIA 4-6 TAHUN BERDASARKAN DATA ANTROPOMETRI KAKI
}

\author{
${ }^{1}$ Garnet Filemon Waluyono \\ ${ }^{1}$ Teknik Industri, Universitas Sebelas Maret Surakarta \\ Igarnetwaluyo@gmail.com
}

\begin{abstract}
ABSTRAK
Sepatu merupakan suatu produk yang memiliki nilai fungsional bagi konsumen. Faktor utama dari nilai fungsional dalam kenyamanan saat memakai sepatu adalah ukuran yang pas di kaki. Ukuran sepatu yang tidak didadasarkan pada ukuran antropometri kaki akan menyebabkan ukuran sepatu tersebut tidak tepat pada ukuran kaki apabila digunakan, ukuran sepatu yang tidak tepat akan menyebabkan cidera dan kelainan bentuk kaki. Sepatu yang digunakan oleh anak-anak sangat penting dan perlu diperhatikan dalam hal ukuran. Pada usia anak dimensi ukura sepatu sangat penting untuk diperhatikan dibanding dengan dimensi ukuran sepatu yag digunakan oleh orang dewasa. Tujuan dari penelitian ini adalah membuat rancangan ukuran sepatu untuk anak perempuan usia 4-6 tahun berdasarkan data pengukuran antropometri kaki. Pengukuran antropometri kaki dilakukan secara manual, selanjutnya hasil dari ukuran antropometri kaki diolah menggunakan metode K-Means Cluster hasil dari pengolahan K-Means Cluster ini yang digunakan untuk merancang ukuran sepatu. Penelitian ini menghasilkan 13 rancangan ukuran sepatu, ukuran sepatu yang dihasilkan dibagi menjadi 3 ukuran, yaitu narrow dengan variasi sebanyak 4 ukuran, medium dengan variasi sebanyak 6 ukuran, dan wide dengan variasi sebanyak 3 ukuran. Ukuran sepatu yang dihasilkan dapat mengakomodari sebesar $73 \%$ dari total responden sebanyak 100 anak perempuan usia 4-6 tahun.
\end{abstract}

Kata Kunci : Sepatu, Antropometri, Ukuran, K-Means Cluster

\section{PENDAHULUAN}

Sepatu adalah alat pelindung kaki dari segala macam gangguan iklim (panas, dingin, hujan) dan benda-benda tajam atau runcing seperti bebatuan dan rumput berduri (Thronton, 1953). Awalnya desain sepatu hanya dibuat berdasarkan nilai fungsi dan guna, yaitu sebagai pelindung kaki dari macam-macam iklim (dingin, panas, dan hujan) serta melindungi kaki saat menginjak suatu benda tajam atau runcing (Basuki, 2010).

Sepatu merupakan suatu produk yang memiliki nilai fungsional bagi konsumen. Untuk memenuhi nilai fungsional tersebut berarti sepatu harus dibuat senyaman mungkin dengan tujuan untuk menunjang aktivitas manusia yang memakainya, telah diasumsikan bahawa sepatu yang nyaman adalah sepatu yang dirancang berdasarkan antropomerti kaki pemakai (Slater K, 1985). Faktor utama dari nilai fungsional dalam kenyamanan saat memakai sepatu adalah ukuran yang pas di kaki (Miller et al, 2000). Ukuran sepatu yang tidak didadasarkan pada ukuran antropometri kaki akan menyebabkan ukuran sepatu tersebut tidak tepat pada ukuran kaki apabila digunakan, ukuran sepatu yang tidak tepat akan menyebabkan cidera dan kelainan bentuk kaki (Luximon, 2005).

Sepatu yang digunakan oleh anak-anak sangat penting dan perlu diperhatikan dalam hal ukuran. Pada usia anak dimensi ukura sepatu sangat penting untuk diperhatikan dibanding dengan dimensi ukuran sepatu yag digunakan oleh orang dewasa (Fritz, 2013). Hal tersebut dikarenakan kaki anak masih mengalami pertumbuhan pada bantuk dan ukurannya (Zhang dan Wang, 2017). Sehingga untuk menentukan ukuran sepatu pada usia anak harus sangat hati-hati dan sepatu yang digunakan anak harus memiliki ruang kelonggaran saat dipakai. Tujuan dari memberikan ruang kelonggaran pada sepatu anak adalah untuk menunjang kesehatan pertumbuhan kaki anak. Kelonggaran untuk panjang 
sepatu harus lebih panjang sebesar 9-15 mm dari panjang kaki (Stansa, 2003). Untuk kenaikan setiap ukuran sepatu dapat menggunakan interval dari 5-10 (Pivecka, 1995).

Dalam penelitian ini sebelumnya telah dilakukan observasi lapangan, untuk mengetahui sepatu yang dipakai oleh anak-anak. Wawancara dilakukan terhadap orang tua yang mempunyai anak dengan usia 4-6 tahun, tujuan dari wawancara ini adalah untuk mendapatkan informasi, apakah sepatu yang selama ini dipakai oleh anak-anak mereka sudah nyaman dalam hal ukuran. Hasil dari wawancara ini ternyata sebanyak 25 dari total 30 responden menyatakan bahwa kesulitan dalam memilih ukuran sepatu yang pas untuk anak mereka.

Perumusan masalah dalam penelitian ini adalah perlunya dilakukan perancangan ukuran sepatu untuk anak perempuan dengan usia 4-6 tahun berdasarkan data antropometri kaki (panjang kaki, lebar kaki, gemur kaki, gemuk kaki, lingkar kaki dari tumit sampai dengan punggung kaki, dan lebar tumit). Tujuan dalam penelitian ini adalah menghasilkan rancangan ukuran sepatu yang nantinya diharapkan dapat digunakan dalam produksi sepatu anak usia 4-6 tahun, sehingga memudahkan dalam hal pemilihan ukuran dan menunjang kesehatan kaki dengan memakai sepatu dengan ukuran pas yang dihasilkan dari pengukuran antropometri kaki.

Beberapa penelitian terdahulu yang mempunyai karakteristik tema penelitian yang sama, tetapi akan berbeda pada metode, subjek penelitian, dan variabel yang digunakan, berikut beberapa penelitian terdahulu yang digunakan sebagai dasar pembanding dalam membuat keterbaruan pada penelitian sekarang. Tahun 1994, oleh Sri Bandi, Soewandi, dan Dwi Asdono Basuki melakukan 2 penelitian yang pertama dengan subjek laki-laki, dan kedua dengan subjek perempuan, kedua subjek diambil dengan tingkatan pendidikan yang sama, yaitu dari muird SD, SLTP, dan SLTA dengan rentang umur 6-17 tahun. Hasil dari penelitian tersebut adalah akomodasi ukuran sepatu dari Perancis (EU) terhadap kaki responden.

Tahun 1994, oleh Suliestiyah Wiryodiningrat dan Dwi Asdono Basuki melakukan penelitian dengan judul Penelitian Standar Ukuran Sepatu Anak-Anak Indonesia. Responden dalam penelitian ini berusia 5-11 tahun, penelitian dilakukan di Yogyakarta. Penelitian tersebut menghasilkan ukuran acuan pada lebar kaki sebagai parameter pembanding untuk ukuran kaki yang lain. Selain itu penelitian ini juga menghasilkan pernyataan bahwa ukuran sepatu yang ada (Inggris, Amerika, dan Perancis) dalam pemberian notasi ukuran dan fitting ukuran ternyata tidak sesuai dengan ukuran kaki orang Indonesia, khususnya untuk kaki anak laki-laki.

Tahun 2016, oleh Yu Chi Lee melakukan penelitian dengan repsonden dalam penelitian ini adalah perempuan yang berusia 20-60 tahun. Penelitian tersebut menghasilkan 80 sistem ukuran baru untuk perempuan di Taiwan. Tahun 2019, oleh Waluyo melakukan peneltian untuk membuat sistem rancangan ukuran sepatu untuk anak laki-laki usia 4-6 tahun, hasil dari penelitian tersebut adalah ukuran sepatu dengan 21 variasi ukuran, dan ukuran yang dihasilkan dapat mengakomodasi $87 \%$ dari total 100 anak laki-laki.

\section{METODE PENELITIAN}

Subjek dalam penelitian ini adalah anak perempuan dengan usia 4-6 tahun. Jumlah responden adalah 100 anak perempuan. Sebaran responden berasal dari 5 daerah di Karesidenan Surakarta, yaitu Kota Solo, Kabupaten Karanganyar, Kabupaten Sukoharjo, Kabupaten Klaten, dan Kabupaten Wonogiri.

\section{Peralatan dan Metode Pengukuran Antropometri Kaki}

Pengukuran antropometri kaki dilakuakan berdasarkan pengukuran manual yang dilakukan oleh Bata (Bata, 1977). Pengukuran dilakukan secara manual mengingat untuk pengukuran secara manual lebih sedikit biaya dan bisa dilakukan dilapangan, tanpa harus mengundang responden ke laboratorium. Pengukuran antropometri dilakukan pada bagian 
panjang kaki, lebar kaki, gemur kaki, gemuk kaki, lingkar kaki dari tumit sampai punggung kaki, dan lebar tumit. Berikut bagian ukuran kaki yang diukur dapat dilihat pada gambar 1.

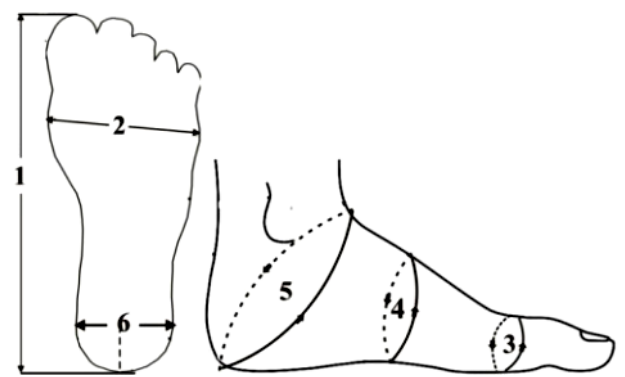

Gambar 1. Pengukuran Antropometri Kaki

(1. Panjang Kaki, 2. Lebar Kaki, 3. Gemur Kaki, 4. Gemuk Kaki,

5. Lingkar Kaki dari Tumit sampai Punggung Kaki, 6. Lebar Tumit).

Pengukuran panjang kaki, lebar kaki, dan lebar tumit dengan cara kaki diletakkan di atas kertas HVS selanjutnya pola kaki digambar dengan pensil tegak lurus, hasil dari pola gambar kaki ini nantinya yang akan diukur dengan penggaris untuk menentukan ukuran panjang kaki, lebar kaki, dan untuk lebar tumit adalah lebar horizontal dari $4 \mathrm{~cm}$ batas kaki paling belakang. Untuk gemur kaki, gemuk kaki dan lingkar kaki tumit sampai punggung kaki menggunkan penggaris pita.

\section{Metode K-Means Cluster}

K-Means Cluster merupakan metode analisis klaster non-hirarki yang dimulai dengan menentukan terlebih dahulu jumlah klasteryang diinginkan. Setelah jumlah klaster diketahui, baru proses klaster dilakukan tanpa mengikuti proses hirarki (Santoso, 2010). Keuntungan dari metode K-Means Cluster adalah bahwa ia memiliki akurasi yang cukup tinggi pada ukuran objek, sehingga algoritma ini relatif lebih terukur dan efisien untuk memproses data dalam jumlah besar. Langkah algoritma dalam proses K-Means Cluster (Praven dan Rama, 2017) :

1. Tentukan nilai $\mathrm{K}$ sebagai jumlah klaster optimal yang di bentuk. Untuk menentukan jumlah cluster yang optimal akan digunakan metode elbow.

2. Bangkitkan K titik pusat klaster (centroid) awal secara random.

3. Hitung jarak setiap objek ke masingmasing centroid dari masing-masing klaster.

4. Alokasikan masing-masing objek ke dalam centroid yang paling terdekat

5. Lakukan iterasi, kemudian tentukan posisi centroid baru

6. Ulangi langkah 3 jika posisi centroid baru tidak sama.

Hasil klaster akhir dari analisis klaster K-means ini nanti yang akan digunakan sebagai pedoman dalam merancang ukuran sepatu untuk anak perempuan usia 4-6 tahun.

\section{Perancangan Sistem Ukuran}

Hasil dari final cluster center yang sudah terbentuk akan digunakan sebagai acuan untuk perancangan sistem ukuran sepatu anak usia 4-6 tahun. Perancangan ukuran pada panjang sepatu akan menggunakan ukuran kelonggaran sebesar 9-15 mm, yang berarti menggunakan interval $6 \mathrm{~mm}$ pada setiap kenaikan ukuran panjang sepatu dan ukuran awal atau ukuran minimal pada panjang sepatu dinaikkan sebesar $9 \mathrm{~mm}$ untuk mendapatkan nilai kelonggaran sepatu yang sehat untuk pertumbuhan kaki. Untuk lebar kaki, gemur kaki, gemuk kaki, lingkar kaki dari tumit sampai punggung kaki, dan lebar tumit menggunakan ukuran kelonggaran sebesar 5-10 mm, pada penelitian ini akan menggunakan nilai interval 10 untuk setiap kenaikan ukuran, dan untuk panjang kaki akan menggunakan nilai interval 7 untuk setiap kenaikan ukuran, sehingga kaki yang dapt diakomodasi oleh panjang sepatu sesuai dengan aturan harus ada kelonggaran 9-15 mm.

\section{HASIL DAN PEMBAHASAN}




\section{Pengolahan Data Antropometri Menggunakan K-Means Cluster}

Sebelum melakukan pengolahan data menggunakan metode $\mathrm{K}$-Means Cluster, langkah awal adalah tentukan dulu berapa jumlah cluster yang optimal dari data yang akan digunakan. Pada penelitian ini akan menggunakan metode elbow. Hasil dari pengolahan data menggunakan metode elbow untuk jumlah klaster yang optimal dapat dilihat pada gambar 2 .

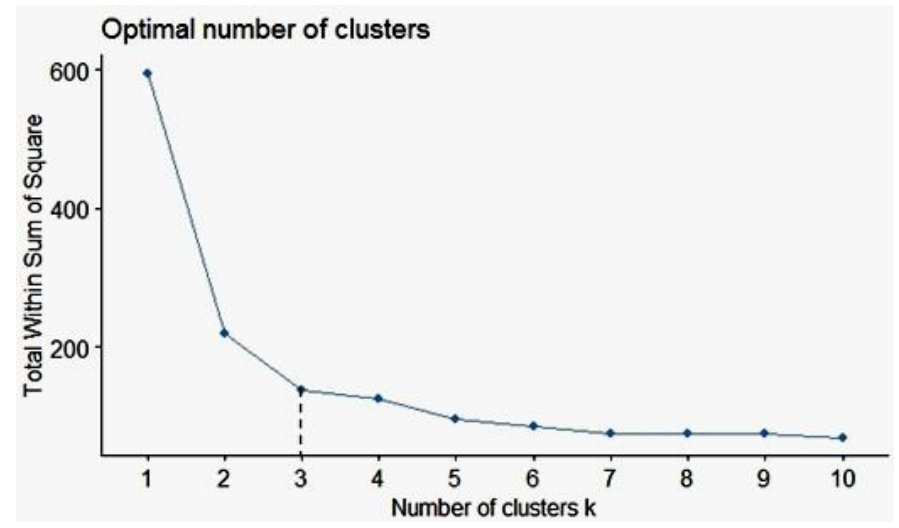

Gambar 2. Grafik Screen Plot Jumlah Klaster Optimal

Pada gambar 2 menunjukkan jumlah klaster yang optimal yaitu sebanyak 3 klaster untuk membagi data antropmetri kaki perempuan usia 4-6 tahun berdasarkan kelompok masing-masing. Setelah dilakukan penentuan jumlah klaster yang optimal selanjutnya data diolah menggunakan metode $K$-Means Cluster dengan pengelompokan menjadi 3 kelompok klaster. Berikut tabel 1 adalah hasil final cluster center.

Tabel 1. Final Cluster Center

\begin{tabular}{|l|r|r|r|}
\hline \multirow{2}{*}{ Antropometri Kaki } & \multicolumn{3}{c|}{ Cluster } \\
\cline { 2 - 4 } & \multicolumn{1}{c|}{1} & \multicolumn{1}{c|}{2} & \multicolumn{1}{c|}{3} \\
\hline Panjang Kaki (mm) & 166,29 & 179,14 & 194,13 \\
\hline Lebar Kaki (mm) & 69,88 & 77,37 & 83,69 \\
\hline Gemur Kaki (mm) & 172,39 & 187,23 & 199,75 \\
\hline Gemuk Kaki (mm) & 172,35 & 188,14 & 199,31 \\
\hline Lingkar dari Tumit-Punggung Kaki (mm) & 215,33 & 226,94 & 241,63 \\
\hline Lebar Tumit (mm) & 45,53 & 52,09 & 59,19 \\
\hline
\end{tabular}

Tabel 1 merupakan hasil akhir pengolahan data menggunakan metode $K$-Means Cluster. Hasil final cluster center tersebut dapat diketahui karakteristik dari masingmasing kelompok, untuk cluster 1 merupakan kaki dengan ukuran kecil, cluster 2 kaki dengan ukuran sedang, dan cluster 3 kaki dengan ukuran besar. Selanjutnya akan dibuat acuan untuk merancang sistem ukuran sepatu. Sebelum membuat ukuran acuan, hasil final cluster center tersebut nilainya akan dibulatkan keatas, berikut hasilnya pada tabel 2 .

Tabel 2. Pembulatan Hasil Final Cluster Center dan Penambahan Ukuran Kelonggaran pada Panjang Kaki

\begin{tabular}{|l|r|r|r|}
\hline \multirow{2}{*}{\multicolumn{1}{|c|}{ Antropometri Kaki }} & \multicolumn{3}{c|}{ Cluster } \\
\cline { 2 - 4 } & \multicolumn{1}{c|}{1} & 2 & \multicolumn{1}{c|}{3} \\
\hline Panjang Kaki (mm) & 167 & 180 & 195 \\
\hline Lebar Kaki (mm) & 70 & 78 & 84 \\
\hline Gemur Kaki (mm) & 173 & 188 & 200 \\
\hline Gemuk Kaki (mm) & 173 & 189 & 200 \\
\hline Lingkar dari Tumit-Punggung Kaki (mm) & 216 & 227 & 242 \\
\hline Lebar Tumit (mm) & 46 & 53 & 60 \\
\hline
\end{tabular}

Batas Acuan untuk Perancangan Ukuran Sepatu 
Pada tahapan ini akan dibuat acuan untuk perancangan ukuran sepatu anak perempuan usia 4-6 tahun. Ukuran acuan ini nantinya akan digunakan sebagai batas-batas dalam merancang ukuran sepatu. Sebelum dibuat acuan akan ditentukan dahulu ukuranukuran sepatu yang akan dihasilkan. Dari hasil klaster yang terbentuk adalah sebanyak 3 klaster, maka untuk ukuran sepatu yang dihasilkan adalah narrow untuk ukuran kecil (cluster 1), medium untuk ukuran sedang (cluster 2), dan wide untuk ukuran besar (cluster 3). Acuan yang dihasilkan dari final cluster center dapat dilihat pada tabel 3.

Tabel 3. Acuan Sebagai Batas-Batas untuk Peracangan Ukuran

\begin{tabular}{|l|c|c|c|}
\hline \multirow{2}{*}{\multicolumn{1}{|c|}{ Dimensi Sepatu }} & \multicolumn{3}{c|}{ Ukuran Sepatu } \\
\cline { 2 - 4 } & Narrow & Medium & Wide \\
\hline Panjang Sepatu / P.S (mm) & P.S $<173,5$ & $173,5-187,5$ & P.S $>187,5$ \\
\hline Lebar Sepatu / L.S (mm) & L.S $<74$ & $74-81$ & L.S $>81$ \\
\hline Gemur Kaki pada Sepatu / Gr.S (mm) & Gr. S $<180,5$ & $180,5-194$ & Gr.S $>194$ \\
\hline Gemuk Kaki pada Sepatu / Gk. S (mm) & Gk.S $<181$ & $181-194,5$ & Gk. S > 194,5 \\
\hline $\begin{array}{l}\text { Lingkar dari Tumit-Punggung Kaki } \\
\text { Sepatu / Lk.TS (mm) }\end{array}$ & Lk. TS $<221,5$ & $221,5-234,5$ & Lk. TS > 234,5 \\
\hline Lebar Tumit pada Sepatu / L.T (mm) & L.T $<49,5$ & $49,5-56,5$ & L.T > 56,5 \\
\hline
\end{tabular}

Tabel 3 merupakan acuan yang digunakan sebagai batas-batas kenaikan dari ukuran narrow ke medium dan dari ukuran medium ke wide dalam membuat rancangan ukuran sepatu.

\section{Perancangan Ukuran Sepatu}

Pada tahapan ini akan dilakukan perancangan ukuran sepatu, sebelum melakukan perancangan ukuran sepatu akan dilakukan pengolahan data menggunakan analisis deskriptif sederhana untuk mengetahui nilai minimal dan nilai maksimal dari data antropometri kaki perempuan usia 4-6 tahun. Nilai minimal antropometri kaki ini nantinya akan digunakan sebagai nilai awal untuk ukuran sepatu. Tabel 4 merupakan hasil dari analisis deskriptif sederhana pada data antropometri kaki perempuan usia 4-6 tahun.

Tabel 4. Analisis Desktriptif Sederhana Data Antropometri Kaki Perempuan Usia 4-6 tahun

\begin{tabular}{|l|c|r|r|r|r|}
\hline \multicolumn{1}{|c|}{ Variabel } & N & Range & Minimum & Maximum & \multicolumn{1}{c|}{ Mean } \\
\hline Panjang Kaki & 100 & 43,00 & 160,00 & 203,00 & 175,2400 \\
\hline Lebar Kaki & 100 & 27,00 & 63,00 & 90,00 & 74,7100 \\
\hline Gemur Kaki & 100 & 52,00 & 163,00 & 215,00 & 181,9600 \\
\hline Gemuk Kaki & 100 & 57,00 & 163,00 & 220,00 & 182,1900 \\
\hline Lingkar dari Tumit-Punggung Kaki & 100 & 49,00 & 206,00 & 255,00 & 223,6000 \\
\hline Lebar Tumit & 100 & 24,00 & 42,00 & 66,00 & 50,0100 \\
\hline
\end{tabular}

Setelah diketahui nilai minumum pada data untuk digunakan sebagai nilai awal dalam perancanga ukuran, selanjutnya adalah melakukan perancangan ukuran sepatu berdasarkan batas acuan sesuai pada tabel 3. Untuk ukuran panjang sepatu akan dimulai dari nilai $169 \mathrm{~mm}$, karena aturan untuk panjang sepatu anak harus lebih panjang 9-15 mm dari panjang kaki yang berguna sebagai ruang pertumbuhan kaki.

Ukuran sepatu yang dihasilkan akan dibagi menjadi 3 kelompok ukuran, yaitu ukuran narrow, medium, dan wide. 
Tabel 5. Ukuran Sepatu Kecil (Narrow)

\begin{tabular}{|c|c|c|c|c|c|c|}
\hline $\begin{array}{c}\text { Panjang } \\
\text { Sepatu } \\
(\mathrm{mm})\end{array}$ & $\begin{array}{c}\text { Lebar } \\
\text { Sepatu } \\
(\mathrm{mm})\end{array}$ & $\begin{array}{c}\text { Gemur } \\
\text { Kaki pada } \\
\text { Sepatu } \\
(\mathrm{mm})\end{array}$ & $\begin{array}{c}\text { Gemuk } \\
\text { Kaki pada } \\
\text { Sepatu } \\
(\mathrm{mm})\end{array}$ & $\begin{array}{c}\text { Lingkar } \\
\text { dari Tumit- } \\
\text { Punggung } \\
\text { Kaki } \\
\text { Sepatu } \\
(\mathrm{mm})\end{array}$ & $\begin{array}{c}\text { Lebar } \\
\text { Tumit pada } \\
\text { Sepatu } \\
(\mathrm{mm})\end{array}$ & $\begin{array}{c}\text { Label } \\
\text { Ukuran }\end{array}$ \\
\hline $169-175$ & $63-72$ & $163-172$ & $163-172$ & $206-215$ & $42-51$ & N1A \\
\hline $169-175$ & $63-72$ & $173-182$ & $173-182$ & $216-225$ & $42-51$ & N1B \\
\hline $176-182$ & $63-72$ & $163-172$ & $163-172$ & $206-215$ & $42-51$ & N2A \\
\hline $176-182$ & $63-72$ & $173-182$ & $173-182$ & $216-225$ & $42-51$ & N2B \\
\hline
\end{tabular}

Tabel 5 merupakan rancangan ukuran sepatu narrow untuk kaki kecil. Ukuran sepatu narrow mempunyai 4 label ukuran, yaitu N1A, N1B, N2A, dan N2B.

Tabel 6. Ukuran Sepatu Sedang (Medium)

\begin{tabular}{|c|c|c|c|c|c|c|}
\hline $\begin{array}{c}\text { Panjang } \\
\text { Sepatu } \\
(\mathrm{mm})\end{array}$ & $\begin{array}{c}\text { Lebar } \\
\text { Sepatu } \\
(\mathrm{mm})\end{array}$ & $\begin{array}{c}\text { Gemur } \\
\text { Kaki pada } \\
\text { Sepatu } \\
(\mathrm{mm})\end{array}$ & $\begin{array}{c}\text { Gemuk } \\
\text { Kaki pada } \\
\text { Sepatu } \\
(\mathrm{mm})\end{array}$ & $\begin{array}{c}\text { Lingkar } \\
\text { dari Tumit- } \\
\text { Punggung } \\
\text { Kaki } \\
\text { Sepatu } \\
(\mathrm{mm})\end{array}$ & $\begin{array}{c}\text { Lebar } \\
\text { Tumit pada } \\
\text { Sepatu } \\
(\mathrm{mm})\end{array}$ & $\begin{array}{c}\text { Label } \\
\text { Ukuran }\end{array}$ \\
\hline $183-189$ & $73-82$ & $173-182$ & $173-182$ & $216-225$ & $52-61$ & M1A \\
\hline $183-189$ & $73-82$ & $183-192$ & $183-192$ & $226-235$ & $52-61$ & M1B \\
\hline $183-189$ & $73-82$ & $193-202$ & $193-202$ & $226-235$ & $52-61$ & M1C \\
\hline $190-196$ & $73-82$ & $173-182$ & $173-182$ & $216-225$ & $52-61$ & M2A \\
\hline $190-196$ & $73-82$ & $183-192$ & $183-192$ & $226-235$ & $52-61$ & M2B \\
\hline $190-196$ & $73-82$ & $193-202$ & $193-202$ & $226-235$ & $52-61$ & M2C \\
\hline
\end{tabular}

Tabel 6 merupakan rancangan ukuran sepatu medium untuk kaki sedang. Ukuran sepatu medium mempunyai 6 label ukuran, yaitu M1A, M1B, M1C, M2A, M2B, dan M2C.

Tabel 7. Ukuran Sepatu Besar (Wide)

\begin{tabular}{|c|c|c|c|c|c|c|}
\hline $\begin{array}{c}\text { Panjang } \\
\text { Sepatu } \\
(\mathrm{mm})\end{array}$ & $\begin{array}{c}\text { Lebar } \\
\text { Sepatu } \\
(\mathrm{mm})\end{array}$ & $\begin{array}{c}\text { Gemur } \\
\text { Kaki pada } \\
\text { Sepatu } \\
(\mathrm{mm})\end{array}$ & $\begin{array}{c}\text { Gemuk } \\
\text { Kaki pada } \\
\text { Sepatu } \\
(\mathrm{mm})\end{array}$ & $\begin{array}{c}\text { Lingkar } \\
\text { dari Tumit- } \\
\text { Punggung } \\
\text { Kaki } \\
\text { Sepatu } \\
(\mathrm{mm})\end{array}$ & $\begin{array}{c}\text { Lebar } \\
\text { Tumit pada } \\
\text { Sepatu } \\
(\mathrm{mm})\end{array}$ & $\begin{array}{c}\text { Label } \\
\text { Ukuran }\end{array}$ \\
\hline $197-206$ & $83-92$ & $193-202$ & $193-202$ & $234-243$ & $62-71$ & W1A \\
\hline $197-206$ & $83-92$ & $203-212$ & $203-212$ & $244-253$ & $62-71$ & W1B \\
\hline $197-206$ & $83-92$ & $213-222$ & $213-222$ & $244-253$ & $62-71$ & W1C \\
\hline
\end{tabular}

Tabel 7 merupakan rancangan ukuran sepatu wide untuk kaki besar. Ukuran sepatu wide mempunyai 3 label ukuran, yaitu W1A, W1B, dan W1C.

\section{Cover Factor Rancangan Ukuran Sepatu}

Validasi hasil rancangan ukuran sepatu pada penelitian ini dilakukan dengan cover factor. Hasil akomodasi ukuran dari rancangan sepatu yang dihasilkan dapat dilihat pada tabel 8 . 
Tabel 8. Akomodasi Ukuran Sepatu

\begin{tabular}{|c|c|c|c|c|}
\hline Cluster & $\begin{array}{c}\text { Total } \\
\text { Responden } \\
(\%) \\
\end{array}$ & $\begin{array}{c}\text { Label } \\
\text { Ukuran }\end{array}$ & $\begin{array}{c}\text { Cover Rate } \\
(\%)\end{array}$ & $\begin{array}{c}\text { Jumlah Tidak } \\
\text { Masuk } \\
\text { Ukuran }(\%) \\
\end{array}$ \\
\hline \multirow{4}{*}{$\begin{array}{c}\text { Cluster } 1 \\
\text { (Kecil/ } \\
\text { Narrow) }\end{array}$} & \multirow{4}{*}{49} & N1A & 21 & \multirow{4}{*}{11} \\
\hline & & N1B & 3 & \\
\hline & & $\mathrm{N} 2 \mathrm{~A}$ & 2 & \\
\hline & & N2B & 12 & \\
\hline \multirow{6}{*}{$\begin{array}{l}\text { Cluster } 2 \\
\text { (Sedang/ } \\
\text { Medium) }\end{array}$} & \multirow{6}{*}{35} & M1A & 7 & \multirow{6}{*}{7} \\
\hline & & M1B & 10 & \\
\hline & & M1C & 4 & \\
\hline & & M2A & 1 & \\
\hline & & M2B & 6 & \\
\hline & & $\mathrm{M} 2 \mathrm{C}$ & 0 & \\
\hline \multirow{3}{*}{$\begin{array}{c}\text { Cluster } 3 \\
\text { (Besar/ Wide) }\end{array}$} & \multirow{3}{*}{16} & W1A & 3 & \multirow{3}{*}{9} \\
\hline & & W1B & 3 & \\
\hline & & W1C & 1 & \\
\hline \multicolumn{3}{|c|}{ Total (\%) } & 73 & 27 \\
\hline
\end{tabular}

Tabel 8 menunjukkan akomodasi ukuran sepatu hasil rancangan terhadap responden dalam penelitian ini. Sebanyak 73\% dari 100 responden anak perempuan usia 4-6 tahun dapat diakomodasi dengan ukuran sepatu yang sudah dihasilkan. Untuk cover factor yang didapatkan pada hasil rancangan ukuran sepatu yang mengakomodasi kaki responden adalah sebesar $73 \%$. Menurut Zakaria (2011), cover factor untuk sebuah produk yang dikanakan manusia sebaiknya berkisar antara $65-80 \%$ yang berarti ukuran tersebut dapat mengakomodasi $65-80 \%$ dari seluruh populasi.

\section{KESIMPULAN DAN SARAN}

\section{Kesimpulan}

Penelitian ini menghasilkan ukuran sepatu untuk perempuan usia 4-6 tahun, ukuran sepatu dirancang berdasarkan hasil pengukuran antropometri kaki, yaitu panjang kaki, lebar kaki, gemur kaki, gemuk kaki, lingkar dari tumit sampai punggung kaki, dan lebar tumit. Ukuran yang dihasilkan adalah sebanyak 13 ukuran dengan variasi ukuran untuk sepatu dengan ukuran kecil (narrow) mempunyai 4 variasi ukuran, sepatu dengan ukuran sedang (medium) mempunyai 6 variasi ukuran, dan sepatu dengan ukuran besar (wide) mempunyai 3 variasi ukuran. Hasil dari ukuran sepatu tersebut dapat mengakomodasi 73\% dari total sejumlah 100 responden perempuan usia 4-6 tahun.

\section{Saran}

Ukuran sepatu yang dihasilkan pada penelitian ini dapat digunakan untuk pembuatan sepatu secara mass production. Untuk sepatu yang dibuat berdasarkan pesanan individu perlu dilakukan pengukuran kaki secara langsung dan untuk menunjang kenyamanan perlu diukur lebih banyak pada bagian-bagian antropometri kaki.

\section{DAFTAR PUSTAKA}

Basuki Dwi Asdono. 2010. Teknologi Sepatu. Yogyakarta: Akademi Teknologi Kulit.

Basuki Dwi Asdono., Sri Bandi., Soewardi. 1994. Penelitian Tentang Ukuran Acuan Sepatu Pelajar Pria tingkat SD, SLTP dan SLTA. Vol. IX. No. 17.

Basuki Dwi Asdono., Sri Bandi., Soewardi. 1994. Penelitian Tentang Ukuran Acuan Sepatu Pelajar Wanita tingkat SD, SLTP dan SLTA. Vol. IX. No. 19.

Bata. 1977. Footwear Design and Manufacture, Bata Shoes Company Private Limited, Main Factory Batanagar, India. 
Fritz, B.B., Maunch, M. 2013. Foot Development in Childhood and Adolescence. Foot Growth, Handbook of Footwear Design and Materials.

G F Waluyono., Bambang S., Eko P. 2019. The Design of Shoe Sizes for Boys Aged 4-6 Years Old Based on Foot Anthropometric Data: Length Foot, Width Foot, and Foot Ball Circumference. IOP Conference Series: Materials Science and Engineering. (598) 012056.

Luximon, A., Goonetilleke, R.S. and Zhang, M. 2005. 3D Foot Fhape Generation From $2 D$ Information. Ergonomics, Vol 48(6), 625-641.

Miller, J.E., Nigg, B.M., Liu W., Stefanyshyn D. J.,Nurse M. A. 2000. Influence of Foot, Leg and Shoe Characteristics on Subjective Comfort. Foot \& Ankle International. Vol. 21, p. 759-767. American Orthopaedic Foot and Ankle Society.

Pivecka, J., and Laure, S. 1995. The Shoe Last: Practical Handbook for Shoe Designers (1st ed.). Slavicin,Czech Republic: Jan Pivecka Foundation.

Praveen, P. And Rama. 2017. A K-Means Clustering Algorithm on Numeric Data. International Journal of Pure and Applied Mathematics, Vol. 117 (7), 157-164.

Santoso, S. 2010. Statistika Multivariat Konsep \& Aplikasi dengan SPSS. Jakarta: PT. Elex Media Komputindo.

Slater, K. (1985). Human Comfort. Springfield, IL: Charles C Thomas.

Stastna, P. 2003. Level of Footwear by Children and Youth Contrasts With The Health of Their Feet. Paper presented at the International Conference Baltic Textile and Leather, Kauno Technologijos Universitetas, Kaunas.

Thronton, JH. 1953. Texs Book Of Footwear Manufacture Edisi Pertsma. London

Yu Chi-Lee., Wen-Yu Chao., Mao Jiun Wang. 2016. Developing a New Foot Shape and Size System for Taiwanese Female. Taiwan

Zakaria, Norsaadah. 2011. Sizing System for Functional Clothing - Uniform for Childreen. Indian Journal of Fibre and Textile Research : 36, 348-357.

Zhang, D. and Wang, Y. 2017. Study on the Influencing Factors on Comfort Shoes of Children's Shoes. Journal of Business Administration Research, Vol. 6, No. 2. 